\title{
FORMULATION OF MUCOADHESIVE BUCCAL FILMS USING PREGELATINIZED CASSAVA STARCH PHTHALATE AS A FILM-FORMING POLYMER
}

\author{
SILVIA SURINI*, FUNGI GOTALIA, KURNIA SARI SETIO PUTRI
}

Laboratory of Pharmaceutics and Pharmaceutical Technology Development, Faculty of Pharmacy, Universitas Indonesia, Depok, 16424, Indonesia. Email: silvia@farmasi.ui.ac.id

Received: 05 June 2018, Revised and Accepted: 15 October 2018

\section{ABSTRACT}

Objective: This study aimed to compare the characteristics of four buccal films formulated with phthalylated cassava starch and their drug delivery potentials.

Methods: An alternative to conventional (oral) drug administration is to administer drugs in a buccal film; however, the required dosage must be dissolved in a film-forming polymer with suitable mechanical and mucoadhesive characteristics. Previous studies have produced excipients by physically and chemically modifying starch, such as by completely pregelatinization and phthalylation it in an aqueous medium under alkaline conditions ( $\mathrm{pH} 8-10)$. This produced a pregelatinized cassava starch phthalate (PCSPh) powder with a high degree of substitution (0.0541 \pm 0.0019$)$, thus giving it different physical, chemical, and functional characteristics than unphthalated PCS.

Results: PCSPh in 4.5\% and 6\% (w/w) concentrations was used as excipients for producing four formulations of buccal film. One film had the most suitable characteristics, with an ex vivo mucoadhesion time of $57.1 \pm 20.3 \mathrm{~min}$, tensile strength of $0.84 \pm 0.02 \mathrm{~N} / \mathrm{mm}^{2}$, and a more rapid drug release profile than two of the other film types produced. Our tests also revealed that the best film tended to not change physically when moistened (percentage moisture absorption was $139 \%$ and moisture loss was 65\%).

Conclusion: Thus, we predict that PCSPh could be adequately formulated to provide mucoadhesive buccal films with an appropriate drug release profile.

Keywords: Buccal film, Film-forming polymer, Modification of starch, Mucoadhesive, Pregelatinized cassava starch phthalate.

(C) 2018 The Authors. Published by Innovare Academic Sciences Pvt Ltd. This is an open access article under the CC BY license (http://creativecommons. org/licenses/by/4. 0/) DOI: http://dx.doi.org/10.22159/ijap.2018.v10s1.50

\section{INTRODUCTION}

Although patients and clinicians prefer orally administered drugs, this type of delivery system has a number of disadvantages, including hepatic first-pass metabolism, gastric irritation, and enzymatic degradation within the gastrointestinal tract. The buccal route for delivering drugs has been advocated as an alternative to oral administration because venous blood reaches the heart directly through the internal jugular vein [1]. The principle of mucoadhesion offers a simple and practical approach to achieve increased mucoadhesive residence time for the dosage form and sustained drug release [2]. Moreover, transmucosal absorption of drugs into the circulation system provides a number of other advantages, such as rapid action, high permeability, and high blood flow. Furthermore, the buccal area is easily accessible for both applying and removing drug delivery devices [3]

Biopolymers (e.g., starches) are commonly used to make thermoplastic buccal films because they are biodegradable. Since utilization of starch in pharmaceutical dosage forms is sometimes limited by its solubility (unsoluble in cold-water) and mechanical properties (low flexibility and tensile strength), some modification (physical, chemical, and enzymatically) are required to improve the characteristic of starch [4]. Here, we chose pregelatinized cassava starch phthalate (PCSPh) (a starch derivative) as an excipient for three different buccal films. We then compared characteristics of these films with a film prepared with PCS. We used diltiazem hydrochloride (DH), a calcium channel blocker belonging to the benzothiazepine family, as our drug model because it is widely prescribed for hypertension and angina. Nevertheless, it has poor bioavailability (30-40\%) and a short biological half-life (3-5 h) with an initial dose of 60-120 mg delivered twice daily [5]. We aimed to develop a buccal film to enhance drug absorption as a means to increase its bioavailability.

\section{MATERIALS AND METHODS}

\section{Materials}

Various combinations of the following materials were combined as formula for four different mucoadhesive buccal film tablets: diltiazem hydrochloride (Piramal, India), PCSPh (Universitas Indonesia, Indonesia), glycerol (Brataco, Indonesia), propylene glycol (Brataco, Indonesia), aspartame (Vitasweet, China), sodium hydroxide (Merck, Germany), potassium dihydrogen phosphate (Merck, Germany), goat buccal sections (Pasar Agung, Indonesia), and Aquadest (Brataco, Indonesia).

\section{Preparing DH mucoadhesive buccal films}

We used four different formulas to create mucoadhesive buccal film tablets (Table 1). The buccal film tablets were prepared using the solvent casting method with aquadest as the solvent for all films. Each film type was formulated by combining a dispersed polymer in aquadest with a solution of DH (an active pharmaceutical ingredient), aspartame, and a solution of plasticizer (containing propylenglycol and glycerol). Each solution was mixed with a magnetic stirrer until thoroughly homogenized. The mixture then was left to stand for several hours at room temperature to ensure the production of a bubble-free solution. The resulting solution was then poured in a Tupperware mold and dried in an oven at $50^{\circ} \mathrm{C}$ until a flexible film formed. After drying, the film was carefully removed from the Tupperware mold. Equal dosages were created by cutting the film so that each film tablet contained $25 \mathrm{mg}$ diltiazem $\mathrm{HCl}$. Each tablet was then packed in aluminum foil and stored in a glass desiccator at room temperature until tested [6].

\section{Film morphology}

Morphologies of the buccal films were observed on various surfaces (topside, bottom side, and cross-section) using a scanning electron microscope (SEM). 
Table 1: Formulation of diltiazem $\mathrm{HCl}$ mucoadhesive buccal films

\begin{tabular}{lllll}
\hline Ingredients & \multicolumn{2}{l}{ Formula } & & \\
\cline { 2 - 5 } & F1 & F2 & F3 & F4 \\
\hline PCSPh (pregelatinized cassava starch phthalate (PCS)) & 4.5 & 6 & - & 6 \\
PCS & - & - & 6 & - \\
DH & 2.491 & 2.491 & 2.491 & 2.491 \\
Propylene glycol & 1.125 & 1.125 & 1.125 & 1.125 \\
Glycerol & 0.9 & 0.9 & 0.9 & 0.9 \\
Aspartame & 0.2 & 0.2 & 0.2 & 0.2 \\
Aquadest & 90.784 & 89.284 & 89.284 & 88.609 \\
\hline
\end{tabular}

DH: Diltiazem hydrochloride

\section{Film weight and thickness}

To evaluate film weight, five random samples of every film composition (four formulations) were weighed individually on a digital balance (Mettler Toledo AL204, USA) and then the average weight for each type of film was calculated. The thickness of each film type was determined by measuring each type at five different locations (at center and four peripheral locations) using a micrometer screw gauge (Din: 863/11, England). Then, the mean of film thickness was calculated for each film type.

\section{Surface $\mathbf{p H}$}

We used the method adopted by Bottenberg et al., to determine the surface $\mathrm{pH}$ of a tablet with a $\mathrm{pH}$-meter [7]. The films were allowed to swell by keeping them in contact with $5 \mathrm{~mL}$ of distilled water ( $\mathrm{pH} 6.5 \pm 0.1$ ) for $2 \mathrm{~h}$ at room temperature. $\mathrm{pH}$ for swollen films was obtained by placing the glass electrode of the $\mathrm{pH}$-meter (Eutech $\mathrm{pH} 510$, Singapore) in contact with the microenvironment of the swollen film and allowing it to equilibrate for $1 \mathrm{~min}$. The average $\mathrm{pH}$ of three measurements was reported.

\section{Moisture content}

The moisture content of each film (mean of triplicate readings) was determined and recorded using a moisture content analyzer (Adam AMB50, UK) at $105^{\circ} \mathrm{C}$

\section{Folding endurance}

Three random films of each formulation (type) were cut into $1.8 \times 2.5 \mathrm{~cm}$ rectangles. To obtain the folding endurance of the buccal films, The film was repeatedly folded at the same place until it broke or until it folded more than 300 times at the same crease without breaking. The number of folds before breaking provided a value of folding endurance [8].

\section{Percent moisture absorption (PMA)}

An absorption test (using percent moisture) was performed to quantify the physical stability of each buccal film type under high humidity conditions. To do this, three film pieces were excised and weighed. Then, the films were placed in a desiccator containing a saturated solution of sodium chloride while maintaining the humidity inside the desiccator at $70 \%$. After 3 days the films were removed, weighed and PMA was calculated. Average PMA of three films was calculated by dividing (final weight - initial weight with initial weight then times $100 \%$.

\section{Percent moisture loss (PML)}

PML was determined to evaluate the integrity of each film type under dry conditions. Three film pieces were excised and weighed, then placed them in a desiccator containing fuzed anhydrous calcium chloride while maintaining the humidity inside the desiccator at $2 \%$. After 3 days, the film samples were removed and weighed. Average PML was calculated by dividing (final weight - initial weight) with initial weight then times $100 \%$.

\section{Tensile strength and elongation}

To understand the mechanical endurance the films, Tensile strength and elongation were analyzed using a texture analyzer (TA.XT2 Rheoner 3305, Germany) and XTRA Dimension software. The films were placed between two nippers and pulled them apart at a speed of $100 \mathrm{~mm} / \mathrm{min}$.
The force needed to fracture the film was determined by measuring total weight loaded on the string at the moment of breakage. The weight required to break the film was defined as its tensile strength. Tensile strength was determined by dividing force when films fractured (N) with area of film $\left(\mathrm{mm}^{2}\right)$. Percentage of elongation was calculated by dividing final length - initial length with initial length then times $100 \%$.

\section{Swelling index}

The increase in weight due to swelling for each films type was measured by placing samples in a thoroughly cleaned Petri dish with graph paper placed beneath it. Then, $50 \mathrm{~mL}$ phosphate buffer ( $\mathrm{pH}$ 6.8) was poured into the Petri dish. Any increase in the weight of the patch was recorded at $15 \mathrm{~min}$ intervals over a 60 -min period. Percentage of swelling (swelling index) was determined by dividing (Xt-X0) with $\mathrm{X} 0$ then times 100, where $X t$ is the weight of swollen film after time $t$ and $\mathrm{X} 0$ is the weight of a film at the time.

\section{Ex vivo mucoadhesion time}

The time which was needed by each film to detach (ex vivo) from freshly excised goat buccal mucosa was evaluated. The goat buccal tissues were fixed on a glass side with cyanoacrylate glue. A side of the film $(1.8 \times 2.5$ $\mathrm{cm}$ ) was moistened with $1 \mathrm{~mL}$ of phosphate buffer $(\mathrm{pH} 6.8)$ and the goat buccal tissue was pasted to it by applying a light force (with a fingertip) for $20 \mathrm{~s}$. A beaker glass was filled with $200 \mathrm{~mL}$ of phosphate buffer $\mathrm{pH}$ 6.8) and maintained it at $37^{\circ} \mathrm{C}$. Buffer solution in the beaker glass was stirred at $50 \mathrm{rpm}$ to simulate the environment of a buccal cavity. Film adhesion were observed, and the time required for the film to detach from the buccal tissue was recorded.

\section{In vitro mucoadhesion}

Mucoadhesion strength in vitro was evaluated using a texture analyzer. Goat buccal sections to model mucosa was used for these experiments. First, goat buccal sections were kept in a phosphate buffer (pH 6.8) under refrigeration. A buccal film section was removed from the refrigerator and attached to buccal tissue for $50 \mathrm{~s}$. Then, tissue and film were attached to a texture analyzer plate. The texture analyzer probe was operated at a force of $150 \mathrm{~g}$ force $(\mathrm{gF})$ at a speed $0.5 \mathrm{~mm} / \mathrm{s}$. The probe was then lifted at a speed $1 \mathrm{~mm} / \mathrm{s}$. The curve between time and force were recorded until the film became detached from the tissue surface. This procedure quantified bioadhesive strength in units of $\mathrm{gF}$ [9].

\section{Drug content}

Buccal films of each formulation containing equal amounts of $\mathrm{DH}$ were dissolved into $250 \mathrm{~mL}$ of phosphate buffer ( $\mathrm{pH} \mathrm{6.8)}$ and then stirred and filtered the resulting solution. The amount of DH in each sample was determined spectrophotometrically at at $\lambda 236 \mathrm{~nm}$. Average DH amount of three films was defined as drug content.

\section{In vitro drug release}

In vitro drug release from buccal films was conducted using a modification of dissolution procedure. The dissolution medium consisted of $250 \mathrm{~mL}$ of phosphate buffer solution (pH 6.8). The amount of drug released was measured at $37 \pm 0.5^{\circ} \mathrm{C}$ with a rotation speed of $50 \mathrm{rpm}$. One side of a buccal film was glued to a glass side with an instant adhesive (cyanoacrylate adhesive). The film with object glass 
was placed at the dissolution vessel so that the film form faced upright, thereby allowing the drug to be released only from the upper side of the film. Samples of $5 \mathrm{~mL}$ were withdrawn at pre-determined time intervals and replaced with fresh medium. Samples were analyzed after appropriate dilution by UV spectrophotometry (Shimadzu, Japan) at $\lambda 236 \mathrm{~nm}$. The drug release experiments were conducted in triplicates, and the mean values were plotted against time.

\section{RESULTS AND DISCUSSION}

In this study, the buccal films of diltiazem $\mathrm{HCl}$ were prepared using a solvent casting method. First, various amounts and types of polymers were mixed gradually in aquadest with a magnetic stirrer. The polymers provided a physical and chemical contact with the buccal tissue. The obtained four types of diltiazem $\mathrm{HCl}$ buccal films were characterized in terms of weight, thickness, surface $\mathrm{pH}$, percent moisture absorption, percent moisture loss, swelling index, folding endurance, drug content, in vitro drug release, mucoadhesion strength, mucoadhesion time, tensile strength, and elongation potential. Results of these characterizations are shown in Table 2 . The results were white, thin, soft, little moist, and odorless. Using a SEM, we could see that all films had rough surfaces on the topside, which physically differed among the four formulations (Fig. 1). We expect that such rough surfaces (Figs. 1-3) should provide useful attachment surfaces on mucosal tissue, which, in turn, should allow for a rapid release of a drug (Fig. 4).

There were high correlation between weight and thickness of buccal films (Table 2) and amounts of polymer used in the formulations. Our result showed the higher concentration of polymer in formula, the heavier and thicker the obtained films. Table 2 shows that Formulas 2 and 4 (containing 6\% PCSPh) were heavier and thicker than formula 1 because they contained the more PCSPh polymer. Formula 3 was the heaviest and thickest film, perhaps because the viscosity of PCS is higher than the viscosity of PCSPh.

Considering that acidic or alkaline $\mathrm{pH}$ may irritate buccal mucosa and influence the hydration rate of the polymers, we maintained the films at a surface $\mathrm{pH}$ similar to that of saliva. Thus, all formulations of diltiazem $\mathrm{HCl}$ buccal films were prepared at the range of $\mathrm{pH} 5.6$ - 7.0 (Table 2).

The moisture content of films showed that there was no significant difference among film types (the range in moisture content was 10-13\%). Theoretically, films placed in moist conditions will gain weight because moisture is absorbed in response to the hygroscopic characteristics of the polymer and plasticizer, whereas films placed in dry conditions will lose weight in response to the moisture in films being pulled from the mucosa to surrounding environment. In our study, we used polyols as plasticizers. The tendency of a polyol to absorb water depends on its molecular weight and number of its hydroxyl groups. In our films, moisture absorption (\%PMA) was larger than moisture loss (\%PML) (Table 3). Absorption was increased because the plasticizer was effective in binding with moisture in the environment surrounding the mucosa by interacting with starch molecules and so could retain moisture [10]. The ability of the films to absorb and lose moisture differed by film type (formula) (i.e., PMA: F1 > F2 > F3 > F4; PML: F1 > F3 > F4 > F2).

Tensile strengths and elongation were determined to understand the mechanical endurance of the films we tested. Film plasticization can decrease the molecular interaction between polymers by decreasing fragility and increasing flexibility of the polymers which is representated by tensile strength and elongation [11]. Films that are intended to release a drug through buccal delivery should possess sufficient strength to withstand the mechanical stresses imposed during production, handling, and application. The folding endurance of the films was examined to estimate their abilities to withstand repeated bending, folding, and creasing (at the same location), conditions likely to be encountered during production and transportation. All the prepared films showed sufficient flexibility for easy handling and possessed excellent folding endurance of over than 300 folds.

Tensile strength, defined as the maximum stress which still can be handled by a material, is an indication of the strength and elasticity of a film. We determined that tensile strength increased with polymer content. Among the various formulations we tested, film F2 exhibited the highest tensile strength $(0.84 \mathrm{~N} / \mathrm{mm} 2)$ (Table 2). Effective films made from cassava starch derivatives tend to have the low tensile strength and
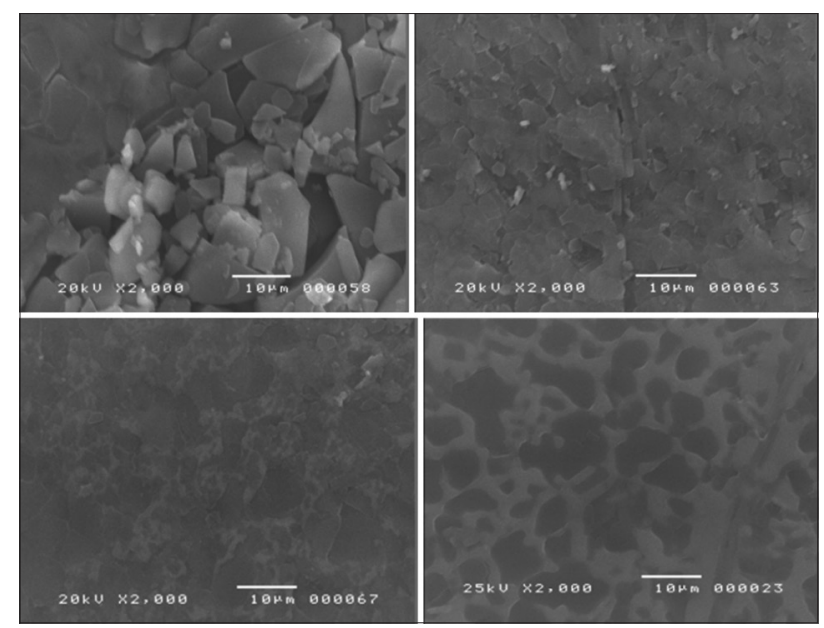

Fig. 1: Scanning electron microscope micrograph of the produced buccoadhesive films (top side with $2000 \times$ magnificancy)
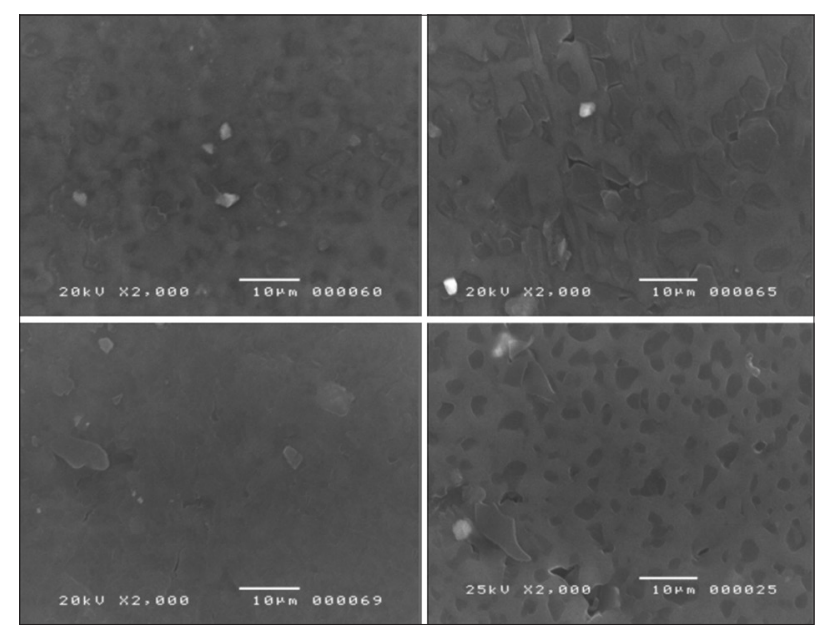

Fig. 2: Scanning electron microscope micrograph of the produced buccoadhesive films (bottom side with $2000 \times$ magnificancy)

Table 2: Characteristics of the produced mucoadhesive buccal films

\begin{tabular}{llllll}
\hline Formula & Weight (g) & Thickness (mm) & Surface pH & Water content (\%) & PMA (\%) \\
\hline F1 & $0.0953 \pm 0.0036$ & $0.16 \pm 0.01$ & $5.89 \pm 0.03$ & $10.58 \pm 3.54$ & $182.21 \pm 45.50$ \\
F2 & $0.1123 \pm 0.0109$ & $0.19 \pm 0.02$ & $5.87 \pm 0.34$ & $12.14 \pm 2.43$ & $9.12 \pm 1.07$ \\
F3 & $0.1554 \pm 0.0028$ & $0.27 \pm 0.01$ & $6.03 \pm 0.05$ & $13.04 \pm 1.66$ & $6.47 \pm 0.34$ \\
F4 & $0.1184 \pm 0.0144$ & $0.19 \pm 0.02$ & $5.77 \pm 0.06$ & $12.85 \pm 1.88$ & $8.29 \pm 0.88$ \\
\hline
\end{tabular}

PMA: Percent moisture absorption, PML: Percent moisture loss 
high elongation potential [12]. The various formulations of plasticizers we used affected films differently (Table 2). We compared percent elongation for film F1 with blank films (those without a plasticizer). Films F1 and F4 did not significantly differ in percent elongation. Different polymers were used in formulations for films F2 and F3, but they did not significantly differ from one another in percent elongation.

\section{Swelling index}

Swelling index of films was measured by observing weight gain of the film after being placed for $4 \mathrm{~h}$ in a phosphate buffer solution
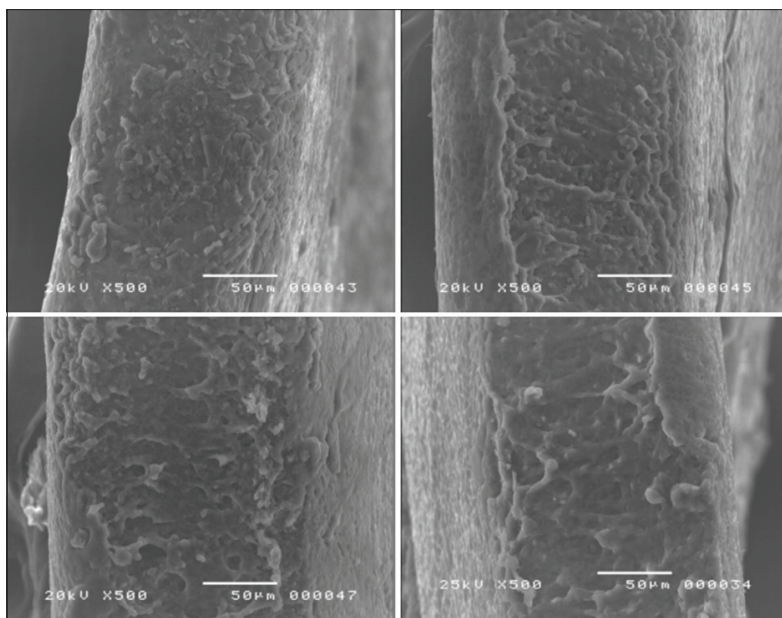

Fig. 3: Scanning electron microscope micrograph of the produced buccoadhesive films (cross-section with $500 \times$ magnificancy)

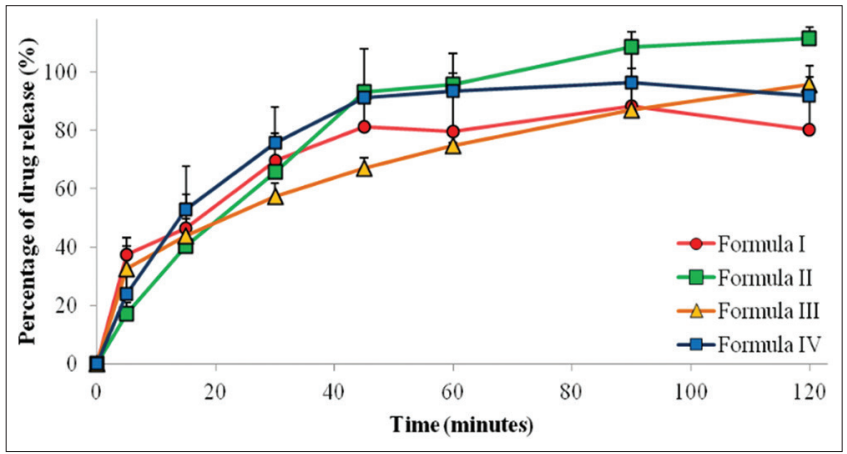

Fig. 4: In vitro dissolution profiles of diltiazem $\mathrm{HCl}$ from the muccoadhesive buccal films
(pH 6.8). Weight gain represents the amount of water that is absorbed (hydrated). Degree of polymer hydration indicates the relative ability a mucoadhesive polymer to induce mobility in a polymer chain, which then allows the polymer and mucin to interpenetrate [8]. The swelling index of a buccal film was an important parameter for quantifying the magnitude of mucoadhesion. Polymer swelling increases mechanical coiling of polymers by opening the interaction site of the hydrogen bond between a polymer and mucosa. We observed that all films retained their forms within the first 30 mins of contact. After $30 \mathrm{~min}$, film F3 started to erode, whereas films F1, F2, and F4 retained their forms, but had begun erode a bit in response to a slight loss in weight. After 45 min, the swelling index of film F3 could not be measured because it had deteriorated completely. From our tests, we determined that PCS films were more easily eroded than PCSPh films.

Film F2's swelling index was the highest after 30 min of contact with mucosa. This was likely because $6 \%$ of PCSPh polymer absorbed more water than $4.5 \%$ of PCSPh polymer. Although the formulation of films F2 and F4 contained the same concentration of polymers, the swelling index of film F4 was less, probably because it had a lower concentration of plasticizer, which, in turn, caused it dissolve more quickly (this led to a smaller weight gain than film F2). For the first 60 min after contact, film F4 experienced more swelling than film F1, but after $60 \mathrm{~min}$, film F1 experienced more swelling (Table 4). We presumed that after the plasticizer had dissolved (after $60 \mathrm{~min}$ ) after which water diffused to the film more rapidly. Swelling index is an important indicator of predicting the rate of drug release from mucosal films. The more hydrated and the higher swelling index of polymer, the higher drug release rate from the film.

\section{Mucoadhesion test}

Our mucoadhesion test determined the strength of a film's adhesion on goat mucosa and the length of time it adheres before detaching (Table 5). Film F2, with greatest swelling, also showed the strongest adhesion to the mucosa. From our analysis of mucoadhesive strength and texture, we determined that there was no significant difference among film types (formulations) in mucoadhesive strength or length of time before detachment. However, our tests of ex vivo mucoadhesion showed disparate results for length of adhesion. Among all tested films, length of time for ex vivo mucoadhesion was highest $(114.7 \pm 9.3 \mathrm{~min})$ for film F3. This was likely because it contained a higher number of hydroxyl groups than the other films, which we formulated with the PCSPh polymer. Thus, film F3 may have had more interpenetration of its polymer with the mucosal tissue. Films $\mathrm{F} 1$ and $\mathrm{F} 4$ had the shortest period of ex vivo mucoadhesion, perhaps due to effects of their plasticizers (i.e., their plasticizers interacted with the polymer chain in a manner that decreased mucin concentration). Although film F2 adhered to the mucosa (ex vivo) longest, this film type did not adhere longer than film F3.

Table 3: Comparison of tensile strength, elongation ability, ex vivo mucoadhesion time, and drug content of the produced buccoadhesive films

\begin{tabular}{lllll}
\hline Formula & Tensile strength $\left(\mathbf{N} / \mathbf{m m}^{\mathbf{2}}\right)$ & Elongation $\mathbf{( \% )}$ & Ex vivo mucoadhesion time (min) & Drug content (mg/film) \\
\hline 1 & $0.34 \pm 0.05$ & $445.87 \pm 75.50$ & $2.7 \pm 2.7$ & $23.3 \pm 2.2$ \\
2 & $0.84 \pm 0.02$ & $272.23 \pm 60.99$ & $57.1 \pm 20.3$ & $24.4 \pm 2.3$ \\
3 & $0.49 \pm 0.09$ & $333.37 \pm 106.16$ & $114.7 \pm 9.3$ & $27.2 \pm 4.2$ \\
4 & $0.17 \pm 0.02$ & $495.50 \pm 28.52$ & $4.7 \pm 3.8$ & $21.3 \pm 3.2$ \\
\hline
\end{tabular}

Table 4: Swelling index (\% swelling) of the produced buccoadhesive films

\begin{tabular}{lllll}
\hline Time (min) & F1 & F2 & F3 & F4 \\
\hline 15 & $266.39 \pm 59.18$ & $335.00 \pm 24.19$ & $297.87 \pm 29.24$ & $367.01 \pm 52.82$ \\
30 & $342.78 \pm 68.15$ & $391.38 \pm 81.32$ & $341.07 \pm 11.84$ & $403.36 \pm 34.25$ \\
45 & $370.09 \pm 46.47$ & $524.08 \pm 61.91$ & $402.51 \pm 36.62$ & $413.81 \pm 24.64$ \\
60 & $404.03 \pm 47.10$ & $546.72 \pm 40.37$ & - & $415.66 \pm 21.55$ \\
120 & $445.74 \pm 38.45$ & $563.74 \pm 5.84$ & - & $425.42 \pm 30.84$ \\
240 & $489.98 \pm 43.84$ & $582.17 \pm 16.77$ & - & $400.86 \pm 23.18$ \\
\hline
\end{tabular}


Table 5: In vitro mucoadhesive strengths for the produced buccoadhesive films

\begin{tabular}{lll}
\hline Formula & Force (gf) & Time (s) \\
\hline F1 & $6.7 \pm 1.0$ & $43.690 \pm 2.721$ \\
F2 & $4.7 \pm 2.2$ & $40.449 \pm 0.949$ \\
F3 & $6.9 \pm 0.8$ & $41.925 \pm 2.181$ \\
F4 & $7.1 \pm 0.8$ & $40.195 \pm 1.680$ \\
\hline
\end{tabular}

\section{Drug release study}

Films F1, F2, and F4 produced an acceptable drug release profile (Fig. 4). That is, all these films released more than $40 \%$ of their drug (diltiazem $\mathrm{HCl}$ ) within $15 \mathrm{~min}$ and more than $80 \%$ within 45 min. After $120 \mathrm{~min}$ (when the films had completely dissolved), film F2 had released 100\% of its drug, higher than any of the other films. This suggests that film F2 is the most appropriate formulation for rapid and complete (100\%) release of drugs.

\section{CONCLUSION}

Low substitution degree of PCS with phthalate successfully modify the excipient characteristics, and its application in low concentration (4.5$6 \%$ ) as film-forming polymer produced muccodhesive buccal film with a rapid release profile.

\section{ACKNOWLEDGMENTS}

All authors gratefully acknowledge Directorate of Research and Community Engagements of Universitas Indonesia for support and research grants.

\section{CONFLICTS OF INTEREST}

Authors declare no conflicts of interest in this research.

\section{REFERENCES}

1. Bukka R, Prakasam K. Evaluation of cellulose polymers for buccal film formulation of rasagiline. Asian J Pharm Clin Res 2014;7:83-7.

2. Mishra SP, Dixit GR, Chavan JI, Kanchan P. Formulation and characterization of mucoadhesive buccal film of ranitidine hydrochloride using Sterculia foetida gum as polymer. Asian J Pharm Clin Res 2015;8:68-71.

3. Repka MA, Chen L, Chan RS. Buccal drug delivery. In: Clive GW, Patrick JC, editors. Controlled Release in Oral Drug Delivery. New York: Springer Science Business Media; 2011. p. 329-59.

4. Putri KS, Surini S, Anwar E. Pregelatinized cassava starch phthalate as film-forming excipient for transdermal film of ketoprofen. Asian J Pharm Clin Res 2013;6:62-6.

5. Moffat AC, Osselton MD, Widdop B. Clarke's Analysis of Drugs and Poisons. London: The Pharmaceutical Press; 2005.

6. Lala R, Thorat AA, Gargote CS, Awari NG. Preparation of buccoadhesive polymeric film of ketoprofen and its evaluation. Asian J Pharm Sci 2011;6:267-74.

7. Bottenberg P, Cleymaet R, de Muynck C, Remon JP, Coomans D, Michotte Y, et al. Development and testing of bioadhesive, fluoridecontaining slow-release tablets for oral use. J Pharm Pharm 1991;43:457-64.

8. Semalty M, Semalty A, Kumar G. Formulation and characterization of mucoadhesive buccal films of glipizide. Indian J Pharm Sci 2008;70:43-8.

9. Mohamed MI, Haider M, Ali MA. Buccal mucoadhesive films containing antihypertensive drug: In vitro/in vivo evaluation. J Chem Pharm Res 2008;3:665-86.

10. Mathew AP, Dufresne A. Plasticized waxy maize starch: Effect of polyols and relative humidity on material properties. Biomacromolecules 2002;3:1101-8

11. Lieberman ER, Guilbert SG. Gas permeation of collagen films as affected by cross-linkage, moisture, and plasticizer content. J Polym Sci 1973;41:33-3.

12. Boonsong P, Laohakunjit N, Kerdchoechuen O, Tusvil P. Properties and permeability of aroma compounds in food through plasticized cassava films. Int Food Res J 2009;16:97-103. 